\title{
Improving saddle stitching line using affordable embedded system
}

\author{
Salam Al-Augby ${ }^{1}$, Ahmed Y. Mjhool ${ }^{2}$, Mohammed W. Alboaldeen ${ }^{3}$, Ali Al-Sabbagh ${ }^{4}$ \\ ${ }^{1,3}$ Faculty of Computer Science and Math (CSM), University of Kufa, Iraq \\ ${ }^{2}$ Information Technology Research and Development Centre (ITRDC), University of Kufa, Iraq \\ ${ }^{4}$ Computer technical department, Al-Taff University College, Iraq \\ ${ }^{4}$ Ministry of Communication, ITPC, Iraq
}

\begin{tabular}{l}
\hline \hline Article Info \\
\hline Article history: \\
Received May 23, 2020 \\
Revised Aug 17, 2020 \\
Accepted Sep 23, 2020 \\
\hline
\end{tabular}

Keywords:

Arduino

Printing house

Saddle

Stitching

Unuversity of Kufa

\begin{abstract}
In most printing factories, the stitching machine is considered as a significant tool in accomplishing the printing process cycle, such as in the Printing House of the University of Kufa (PHUK), complete their jobs using a cheap manual machine, and thus this leads to an increase in the number of employees and work hours. That is because the automated stitching machine of production is very costly. A decent printing house design maximizes production with a minimum investment in new equipment parts. However, a decent PHUK layout alone cannot reach the intended aims unless firmly linked with a developed production line of an automated stitching machine for the purpose of reducing cost, time, and efforts. This article focused on designing and developing automatic saddle stitching machines for folded paper sheet products such as newspapers, magazines, catalogs, exam sheets, etc. using accommodate devices such as Arduino and infrared sensors. Furthermore, the proposed design is applied in PHUK successfully and it showed that the cost of the stitching machine and the manpower is reduced by 60 percent, also the time is reduced by 70 percent. Finally, one of the significant implications of this work is using IT in management of resources.
\end{abstract}

This is an open access article under the CC BY-SA license.

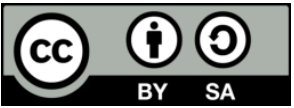

Corresponding Author:

Ali Al-Sabbagh

Al-Taff University College

Ministry of communication

Babylon, Iraq

Email: aalsabbagh2014@my.fit.edu

\section{INTRODUCTION}

A stapler is a mechanical tool used to group two or more sheets of paper together by pushing a thin metal staple through the sheets and they are widely used in government, business, offices, homes, and schools all over the world $[1,2]$. The non-technical problems of stapling machines at bigger printing houses can be categorized into three aspects: first is the economic aspects related to the number of employees, secondly is the quantity of production, and finally is the quality level of production. There is no obvious solution for solving these aspects in one low-cost machine and ignoring the efforts of solving these problems would cost stakeholders time and money $[3,4]$.

According to the manager of PHUK, the manual stapling machine generally makes around 1500 pieces of staple per one hour and this process needs at least four employees [5], hence, the idea of this design comes to solve these problems by upgrading the printing machine to an automatic one. The proposed design used an electronic system to control the multi-functions of the printer, without human intervention. The fully automated stapling machines cost at least more than $\$ 70000$ with installation and training besides other 
technical requirements [6]. Moreover, the traditional manual machines consume more resources in the stapling papers, causing waste in time and resources, and this leads to a negative impact on final productions. For all the above, there is a need to implement an automatic stapling machine to save the efforts, time, money and increase the quality of the stapling productions [7].

This paper is organized as follows. Section 2 discusses the related works of using an automatic printing house in factories. Section 3 describes and explains the components and processes of PHUK. The proposed design, hardware and software components are explained in section 4. Finally, the conclusion in section 5 summarized the key findings of the paper and discussed future work.

\section{RELATED WORKS}

Mayer invented a method and apparatus for tandem stitching of books in a bindery line and this invention accomplishes simultaneous stitching of tandem sets of 1-up gathered signatures [8, 9]. "A shuttle mechanism grips adjacent, consecutive unbound books on a saddle-type gathering conveyor and, in a single stroke, presents both unbound books at a saddle stitcher station for simultaneous binding" [1]. Similarly, the proposed work is designed to carry out six sheets of paper consecutively.

Another invention by Hoffmann and others [9, 10], relates to a method for collating multilayer brochures, comprising a plurality $n$ of signatures with a saddle stitcher. In a first step, a first signature is deposited by a first feeder in a first transport segment, in a second step a second signature is deposited by a second feeder of second transport segment. In accordance with further depositing of further signatures by further investors, an nth signature can be deposited by an nth feeder into an nth transport segment. The signatures thus deposited on a collecting element are transported through the stitching station and the trimming station and laid out in the delivery station. The invention also relates to a saddle stitcher having a control unit which has a machine program for gathering multi-layer brochures, consisting of a plurality $\mathrm{n}$ of signatures. In their invention "Method of operating a saddle stitcher, and saddle stitcher" they used multiple stages of feeder, whereas in our implementation, used one feeder for stitching the papers, more details are fully described in [11-14].

\section{COMPONENTS AND PROCESSES OF PHUK}

The finishing steps of the printing process, refers to all the actions that are executed on printed material after complete printing. This includes binding, stitching of separated sheets of paper together, and decoration such as stamping, embossing or arranged in layers. Figure 1 shows the ordinary steps that were followed by employees in one print cycle [15-17].

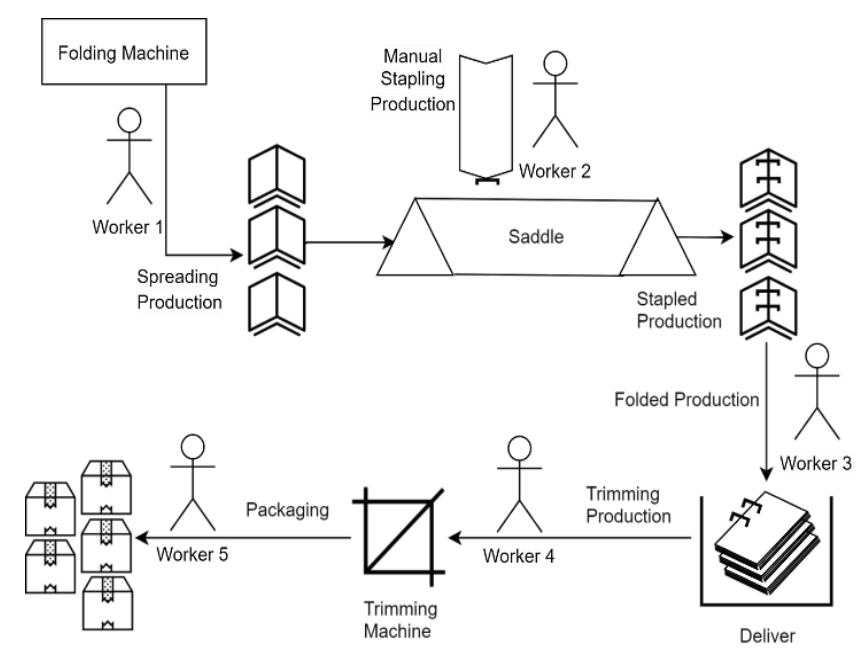

Figure 1. Ordinary steps of one print cycle

There are a lot of ways for binding sheets together; the common methods are listed below:

a. The binding: All the pages are bound to the spine of the cover by using strong glue. This method is used for books, magazines ...etc. 
b. Saddle stitching: The saddle feeds with pre-folded sheet products manually before cutting or trimming any edges as shown in Figure 1. Then, pages are joined by driving metal staples through the center of the folded group of sheets of paper. More, stitching technique is widely used in newspapers, magazines, catalogs, etc.

c. Besides stitching: This type of stitching is less commonly used than the saddle stitching. The metal staples are driven through the pages in parallel to the margin line.

d. Sewing: A cord or thread that is used to stitch sheets of paper together. An adhesive is used in conjunction with the thread. Cord sewing is used for the hard book covers. After that, the book cover should be put under high pressure of weight.

e. Comb stitching technique: The teeth of the comb are placed in drilled slits into arranged combined sheets. This action is almost used for non-folded reports and presentations.

f. Spiral: A spring metal or plastic coil is threaded through parallel holes into a spin of combined sheets. The spiral is typically used for a temporary number of sheets in the notebook.

All those kinds of stitching techniques will contribute to increasing the cost of the automatic stitching machine because that will lead to the need for multi feeder unites along the production line, where a feeder is a complicated machine itself. The number of feeders on the automatic saddle stitching machine would be equal to the number of pages of the folded papers. So the cost of the machine will be multiplied by the number of feeders. Almost all the printing machines are using the same standard size A0 paper to print different sizes of paper productions by montaging all the pages of the magazine, for example, on the two sides of the A0 sheet. Next, after printing, is folding the A0 paper to fit the product size. This involves a series of right-angle folds in which the sheet by many times. One folded sheet makes four pages, two folded right-angle make eight pages, and so on. Other work types require multiple times of parallel folds in which more than one folds which are guided in the same direction that are made in a sheet of production.

\section{DESIGN AND METHODOLOGY}

The proposed implementation aims to take advantage of reordering the stages of the printing process by applying the stage of stitching sheets before the trimming stage. The folded sheet before cutting and trimming is reducing the multiple feeder stages to one feeder because the product is still one piece yet. As a result, this would handle the folded sheets with one feeder and that will give us the advantages of reducing the cost, time, and manpower. The suggested design is implemented using a Raspberry-Pi microcomputer. The efforts in this aspect show the importance of using IT in improving the quality and quantity of products of printing houses and hence reach the management goals [18]. For the proposed design we managed some tools to work together as seen in Table 1.

Table 1. The proposed design required tools

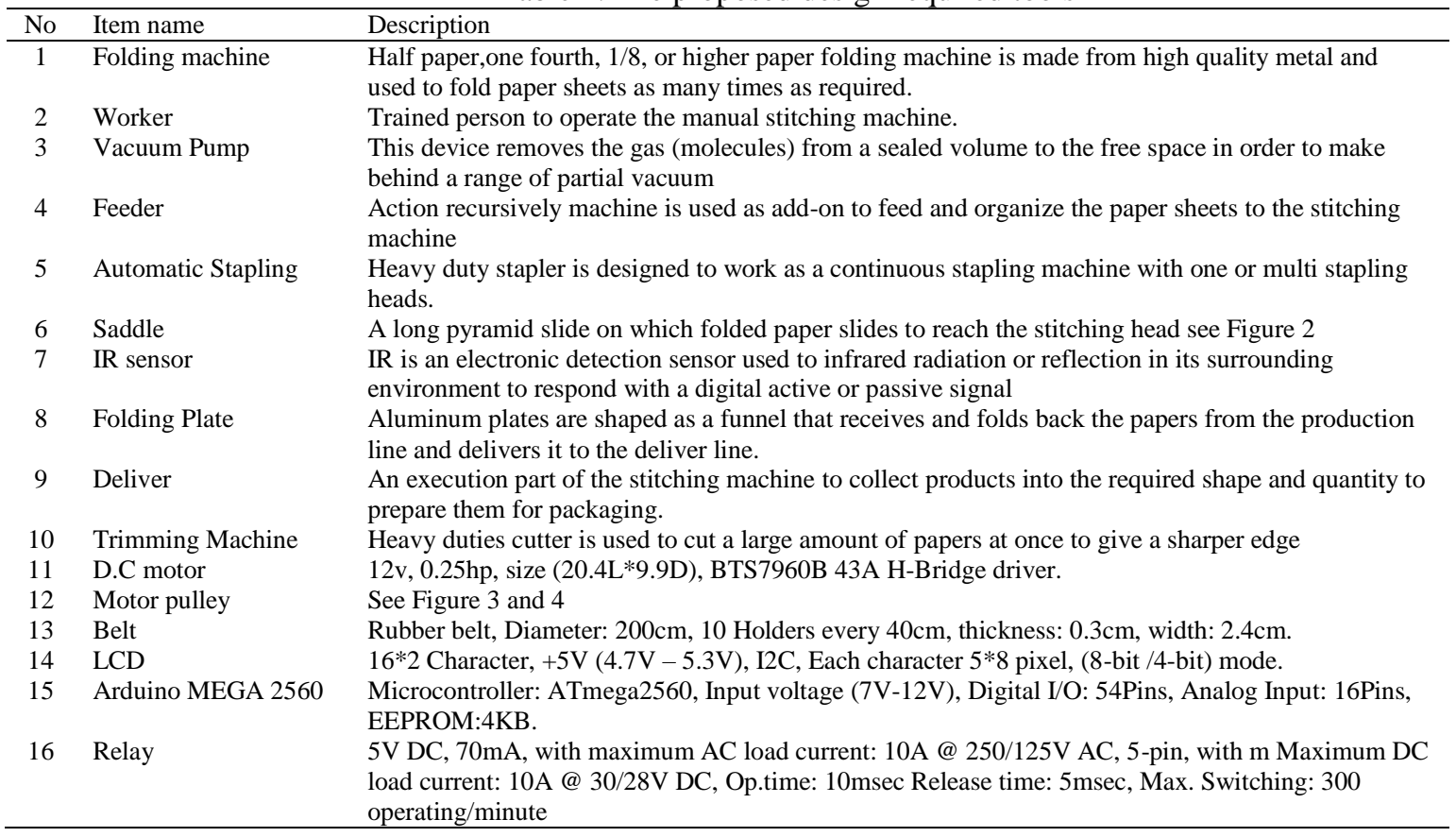


This line work can be divided into three steps, the first one which is going to be a short process on the worker1 when s/he should carry on the production from folding machine and then put it on the feeder in order to let the spreading production tool to spread the production on saddle automatically. The spreading production tool designed and made especially for our work and it consists of vacuum pump, motor, pulley, arms, slider...etc. as seen in Figure 3. Then, the automatic stapling production is timely programmed with the help of IR sensor and sheet movements on the saddle according to belt designed for this purpose as seen in Figure 4.

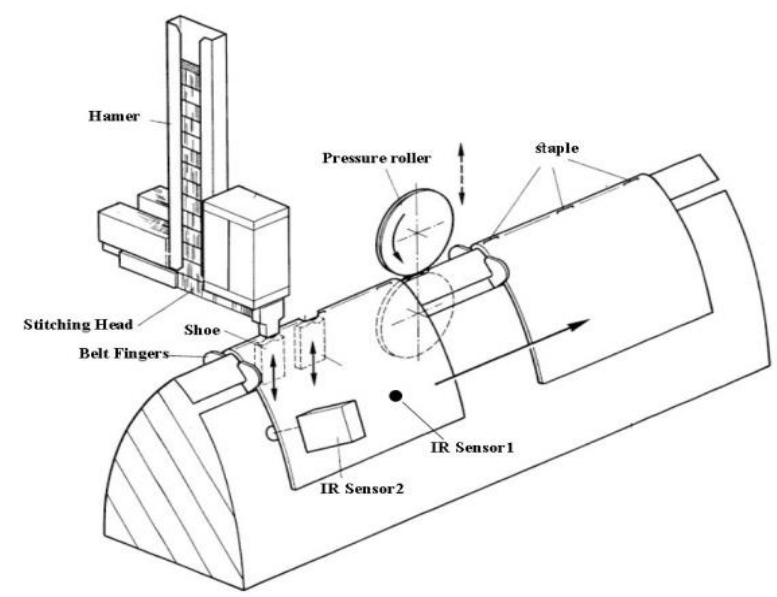

Figure 2. The final stage of production

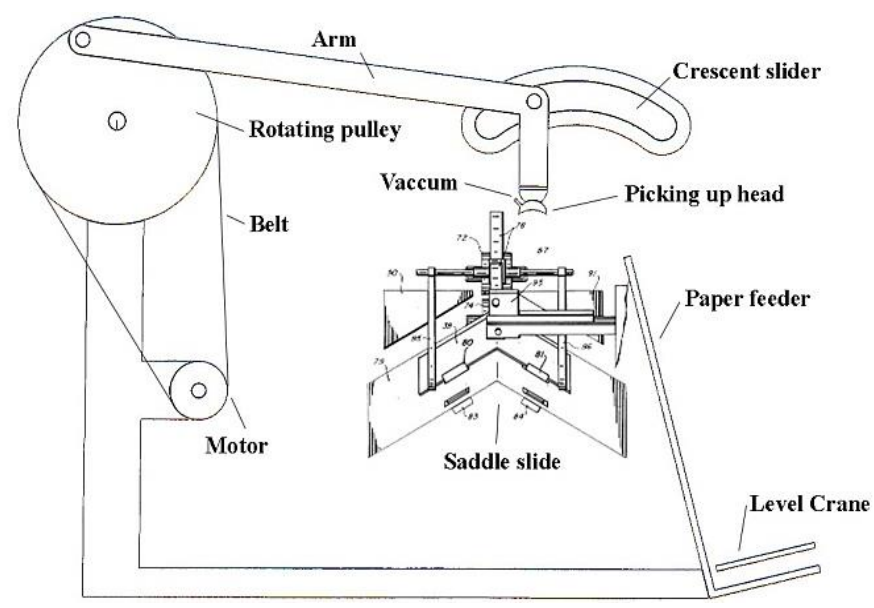

Figure 3. Spreading production tool

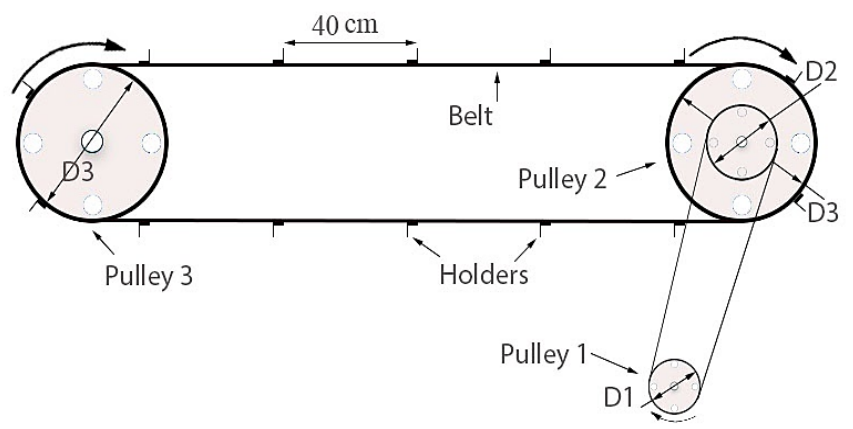

Figure 4. Belt design diagram [17] 
Power $_{\text {out }}=$ Power $_{\text {in }}$, Speed $_{\text {out }} *$ Torque $_{\text {out }}=$ Speed $_{\text {in }} *$ Torque $_{\text {in }}$

Tout $=\omega_{\text {in }} T_{\text {in }} / \omega_{\text {out }}$, velocity of the belt $=\mathrm{V} \mathrm{m} / \mathrm{s}$

The relationship of angular and linear velocity is given $\mathrm{V}=\pi \mathrm{ND}$, the same on $\mathrm{D} 1$, and $\mathrm{D} 2$ then

$\frac{N 1}{N 2}+\frac{D 1}{D 2}$

Product of force and velocity is defined as a mechanical power: $\mathrm{P}=\mathrm{Fv}$, but if one force pulling in opposition to the other, then the net transmitted power is $\mathrm{P}=\mathrm{v} *(\mathrm{~F} 1-\mathrm{F} 2)$, since $\mathrm{v}=\pi \mathrm{ND} \mathrm{P}=\pi \mathrm{ND} *(\mathrm{~F} 1-\mathrm{F} 2)$

$$
\mathrm{T}=\mathrm{F} \times \mathrm{D} / 2 \text {. }
$$

There are two forces pulling in opposite directions, on a given wheel, the net torque is $\mathrm{T}=(\mathrm{D} / 2)$ (F1-F2). Power of the pulley torque is $\mathrm{P}=2 \pi \mathrm{NT}$ or $\mathrm{P}=\omega \mathrm{T}$, when use net torque $\mathrm{P}=2 \pi \mathrm{N} *(\mathrm{D} / 2) *(\mathrm{~F} 1-\mathrm{F} 2)$ and $\mathrm{P}=\pi^{*} \mathrm{ND} *(\mathrm{~F} 1-\mathrm{F} 2)=\mathrm{V}^{*}(\mathrm{~F} 1-\mathrm{F} 2)$ when: $\mathrm{N}$ is the revolution per minute, $\mathrm{D}$ is the diameter of the pulley wheel, $\mathrm{P}$ is the mechanical power, $\mathrm{F}$ is the force, and $\mathrm{T}$ is the torque $[17,18]$.

The belt with holders will order sheets sequentially on the saddle and passing the stapled sheet through the folding plate to drop folded sheets in the deliver line. More, the product will slip along the production line containing the transportation belt to reorganize the products as a timing sequence to be compatible with the sensors I/O signals because of that sensors represent the main variables of the system software. The transportation belt will carry the products straightly on a saddle slide to reach it to the first stapling point which locates depending on the first sensor location. When the products reflect the IR that emitted from the sensor transmitter to the receiver, the positive signal shill sent to the stapling machine to make one staple job during an immediate stop of the transportation belt to move again in the same direction and get ready for the second stable job. That slipping is continuing to take the product to the location of the second sensor, that means the second or last stapling job is done as same as the way of the first. The auxiliary of this stage is the count sensor that counting the number of completed products to send it as a feedback to the microcontroller of the Arduino because we have to use that number into a specified equation [19, 20].

The next step is letting worker2 to take stapled and folded sheets from deliver to the trimming machine to produce individual products that are ready for packaging in the last step by worker3. The three steps and other related components in the Table 1 above can be illustrated in Figure 5 as a work line. The production machine reached the final stage as seen in Figure 2 that responsible for delivering products in the desirable shape, that process tried to fold back the product to the shipping form to be collected as the stakeholder wish.

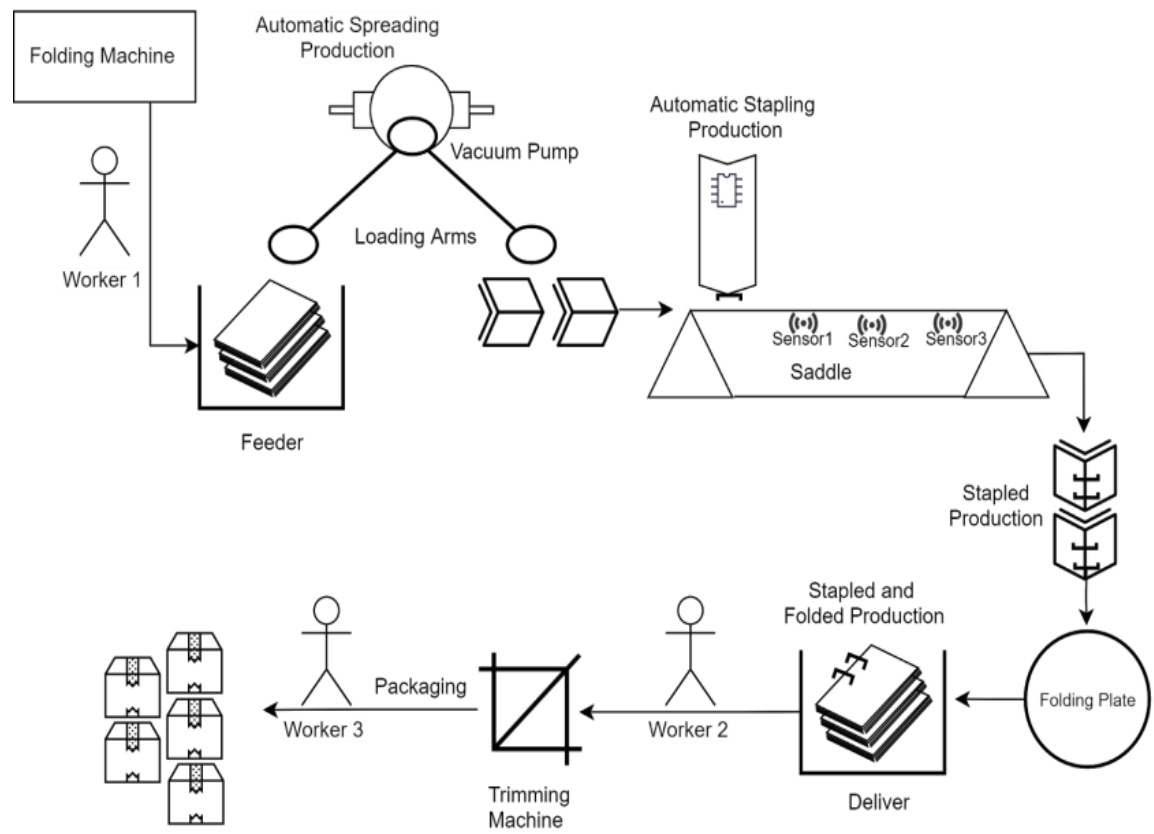

Figure 5. The three steps of the paper flow diagram 
The D.C motor is the main part of the stapling machine, the properties of this motor are summarized by that medium torque and minimum power consumption, and it is coupled with the main pulley which doubles the speed of the transportation belt of the production line. In order to manage high current in the system, the operation, direction and speed of the motor are controlled by BTS-7960 D.C motor driver which is connected to an Arduino MEGA respectively. In general, we use $24 \mathrm{~V} 5$ A multi speed D.C motor as the main motor to give the rotational movement the transformation belt and that motor characterize give us the ability to drive. It uses a high current D.C motor driver and the speed, will be under programming control with important real-time of brakes during the driving board. The other motor used for delivering the sheets to the feeder unit, that motor works frequently by sucking up the product sheet from storage to be dropped on the transformation belt, the belt is $4000 \mathrm{~mm}$ in diameter and has ten holders everyone $40 \mathrm{~cm}$ to reorganize the sheets from the feeder with the help of guides along the production line.

There are three pulleys are used in the product transportation system. First one is called motor pulley, the second one called the gathering pulley and the third one is ending pulley and the diameter of this pulley is equal to the larger diameter of the gathering pulley to keep the constant rate of belt speed.

The sheets of paper will be loaded between the $40 \mathrm{~cm}$ spaces of belt of $400 \mathrm{~cm}$ to move the load on the saddle then when the load reflect the IR of the first sensor that is located on the production line, a positive signal transmitted from the sensor to the Arduino. The Arduino will take an action immediately to stop the transportation belt and make one staple job, and next reach the second IR sensor and make the second staple job and so on.

a. The feeder: is electronic and mechanical tool use air dynamic systems to take the double-folded sheets just from the paper folding machine by two vacuum points.

b. Deliver: in this machine is not complicated compared with the feeder of the same machine, we used aluminum plates formed to fold back the paper sheets of the product as the first form they are fed to the machine.

c. Sensors: sensors are supplied with the power from the main power supply with 5v D.C volts and connected to the Arduino microcontroller by the digital signal pin which is less than $50 \mathrm{~cm}$ long of wire to neglecting the signal copper losses that affecting the low voltage in that signal wire.

d. Control board: containing a group of buttons to be used in emergency cases, manually stop and maintenance. It contains the Arduino board, low and high current relays, electronic protection elements, connections, explanatory lamps, and the status LCD. See the software folwchart of all proposed embedded system in Figure 6 (see in Appendix).

The main brain part of this process is "The Arduino MEGA 2560 is designed for projects that require several I/O lines with more sketch memory and RAM (54 digital I/O pins), 16 analog inputs. Generally, a larger space is the recommended board for 3D printers and other projects (such as robotics). That provides the projects plenty opportunities maintaining the simplicity and effectiveness of the Arduino platform" [19-21]. Besides that, the Arduino receiving the input signals from the three IR sensors. The infrared obstacle avoidance sensor has a pair of infrared transmitting and receiving sensors. The LED emits IR signals with a certain frequency and when an obstacle occurs on the line of IR beam, will be reflected back by the obstacle by the receiver". While the output signals of the Arduino microcontroller are controlling the high and low current relays "The reason of using a $5 \mathrm{~V}$ relay is that the power supply for the relay can be directly given from the Arduino UNO board [22, 23].

e. Relay: is an interface switch between microcontrollers and the AC loads, A simple single pole-single throw relay, with 5 Terminals: 5V, GND, normally open (NO), normally close (NC), and common (COMM). To control the relay by Arduino: a transistor with an additional pin is used, that called control pin on the relay module". Aluminum and Iron plates are used to develop the production stand and all the other covers those needed to fix the electronic parts, control units, and the motors [24, 25].

\section{CONCLUSIONS}

In 2018, a practical experience in PHUK concluded that two well-trained employees were producing around 3000 couples of stapling jobs in one workday. At the same time, the other local printing houses output shall be at the same above rate or relatively less, that encourage us to automate the manual stapling machine. The machinery abilities and the microprocessor that we used in our implementation reached 8000 couples of stapling jobs in one workday. There is no actual need for trained workers to work on the machine and to be satisfied with any worker to feed the products to the machine and the products will be ready to package and transport directly from the machine without any human intervention. Hence, the ordinary practical efforts of the print cycle versus the automatic print cycle in PHUK were experienced, thus, the influence factor between manual and automatic stapling machine is that the quantity is more and the quality is good in production. This work showed that using IT tools can give better results in the case of employing it correctly. 


\section{APPENDIX}

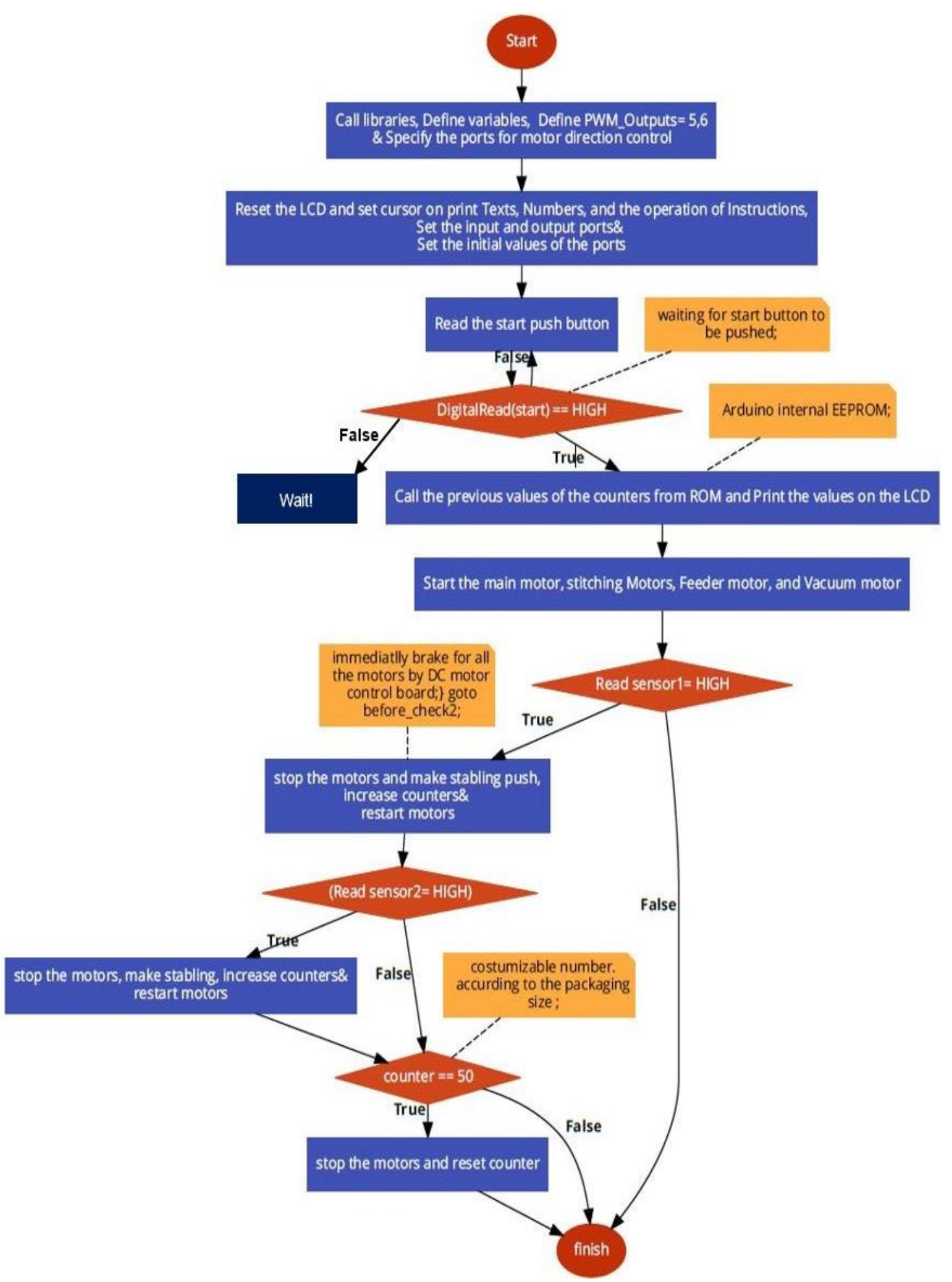

Figure 6. The general flowchart of control board

\section{ACKNOWLEDGEMENTS}

The authors wish to acknowledge the collaboration with the PHUK team for their support, and valuable comments on this contribution. 


\section{REFERENCES}

[1] I. Dunmade, "Lifecycle assessment of a stapling machine" International Journal of Engineering \& Technology, vol. 4, no. 1, pp. 12-19, 2015.

[2] Alam, Hamid, and Yasir Akram., "Automatic Paper Sorting, Stapling and Counting Machine," Diss. Bahria University Islamabad Campus, 2012.

[3] Lan-feng, Qu, "Maintenance and adjustment of stapling machine," Mechanical Research \& Application, vol. 6, 2010.

[4] Berculescu, L., Bălan, E., Mohora, C., and Dogariu, C., "Some Aspects Of Optimization For Printing And Finishing Offset Processes," Annals of the Academy of Romanian Scientists Series on Engineering Sciences, vol. 10, no. 2, pp. 5-18, 2018.

[5] U. S. Patent and Trademark Office, "Awards Patent for Method for Controlling a Feeder of a Gathering-Stitching Machine," Global IP News: Tools and Machinery Patent News, 2016.

[6] Arendt, Holger, et al., "Stitching machine for variable size sheets," U.S. Patent No. 8,876,098, 2014.

[7] Arendt, Holger, "Method for operating a thread stitching machine," U.S. Patent No. 8,967,609, 2015.

[8] Silberbauer, G., U.S. Patent No. 7,032,898. Washington, DC: U.S. Patent and Trademark Office, 2006.

[9] T. Mayer, "Method and apparatus for tandem stitching of books in a bindery line," Google Patent, 1984.

[10] S. Hoffmann, et al.,"Saddle stitcher and method for operating a saddle stitcher" Google Patent, 2009.

[11] Calov, S., "Rebirth of saddle stitching," GATFWORLD, vol. 19, no. 1, pp. 87-89, 2007.

[12] Festa, C. "Saddle stitching: Above and beyond," Gatfworld, vol. 19, no. 3, pp. 32-33, 2007.

[13] Binding machines: Saddle stitching, Printing Impressions, vol. 47, no. 2, pp. 114-114,116, 2004.

[14] Kawatsu, Kenji, Hiroyuki Wakabayashi, and Kohji Yoshie, "Post processing device with saddle stitching," U.S. Patent No. 6,929,256, 2005.

[15] Blum, Jeremy., "Exploring Arduino: tools and techniques for engineering wizardry," John Wiley \& Sons, 2019.

[16] Hughes, John M., "Arduino: A technical reference: A handbook for technicians, engineers, and makers," O'Reilly Media, Inc., 2016.

[17] Adel, Zarifi, Ait Abbas Hamou, and Seghiour Abdellatif, "Design of Real-time PID tracking controller using Arduino Mega 2560for a permanent magnet DC motor under real disturbances," International Conference on Electrical Sciences and Technologies in Maghreb (CISTEM), 2018.

[18] Kipphan, Helmut, "Handbook of print media: technologies and production methods," Chapter seven, Springer Science \& Business Media, 2001.

[19] D. J. Dunn, "Tutorial in solid mechanics, belt mechanicl friction, pulley drive systems," [Online] Available: http://www.freestudy.co.uk/dynamics/pulleys.pdf.

[20] Tătaru, A. I., and C. N. Drugă, "Designing and realization an ECG based the Arduino Mega 2560 development board," IOP Conference Series: Materials Science and Engineering, vol. 568, no. 1, 2019.

[21] Wheat, Dale, "Arduino internals," Apress, 2012.

[22] Mjhool, Ahmed Yaseen, Ali Abbas Al-Sabbagh, and Ruaa A. Saeed Alsabah, "Smart Parking Techniques Based on Internet of things," Journal of Networks and Telecommunication Systems, vol. 1, no. 1, pp. 1-10, 2015.

[23] Paaul Miller, "Arduino uno and arduino mega 2560 get friendly new USB plugs, new look," New York: Newstex. [Online]. Available: https://search-proquest-com.portal.lib.fit.edu/docview/754938332? accountid=27313.

[24] Ariawan, K. U., G. S. Santyadiputra, and I. W. Sutaya, "Design of Hexapod Robot Movement Based on Arduino Mega 2560.[J]," Journal of Physics: Conference Series, vol. 2019, 2009.

[25] Mahalakshmi, G., and M. Vigneshwaran, "IOT based home automation using Arduino," Int. J. Eng. Adv. Res. Technol, vol. 3, no. 8, pp. 1-6, 2017. 